\title{
Oncogenic transformation of Drosophila somatic cells induces a functional piRNA pathway
}

\author{
Delphine Fagegaltier, ${ }^{1}$ Ilaria Falciatori, ${ }^{2}$ Benjamin Czech, ${ }^{2}$ Stephane Castel, ${ }^{3}$ Norbert Perrimon, ${ }^{4}$ \\ Amanda Simcox, ${ }^{5}$ and Gregory J. Hannon ${ }^{1,2,3}$ \\ ${ }^{1}$ Watson School of Biological Sciences, Cold Spring Harbor Laboratory, Cold Spring Harbor, New York 11724, USA; ${ }^{2}$ Cancer \\ Research UK Cambridge Institute, Li Ka Shing Centre, University of Cambridge, Cambridge CB2 ORE, United Kingdom; ${ }^{3}$ The \\ New York Genome Center, New York, New York 10011, USA; ${ }^{4}$ Howard Hughes Medical Institute, Department of Genetics, \\ Harvard Medical School, Boston, Massachusetts 02115, USA; ${ }^{5}$ Department of Molecular Genetics, The Ohio State University, \\ Columbus, Ohio 43210, USA
}

\begin{abstract}
Germline genes often become re-expressed in soma-derived human cancers as "cancer/testis antigens" (CTAs), and piRNA (PIWI-interacting RNA) pathway proteins are found among CTAs. However, whether and how the piRNA pathway contributes to oncogenesis in human neoplasms remain poorly understood. We found that oncogenic Ras combined with loss of the Hippo tumor suppressor pathway reactivates a primary piRNA pathway in Drosophila somatic cells coincident with oncogenic transformation. In these cells, Piwi becomes loaded with piRNAs derived from annotated generative loci, which are normally restricted to either the germline or the somatic follicle cells. Negating the pathway leads to increases in the expression of a wide variety of transposons and also altered expression of some protein-coding genes. This correlates with a reduction in the proliferation of the transformed cells in culture, suggesting that, at least in this context, the piRNA pathway may play a functional role in cancer.
\end{abstract}

[Keywords: Piwi; piRNA; transposon; Ras; Warts; Hippo]

Supplemental material is available for this article.

Received June 1, 2016; revised version accepted July 7, 2016.

The piRNA (PIWI-interacting RNA) pathway is fundamental to successful germ cell development in animals. It has been most extensively studied in flies and mammals, where three PIWI family proteins bind to a class of small RNAs 23-30 nucleotides (nt) in length that are enriched for sequences corresponding to repetitive, mobile genetic elements (Aravin et al. 2007a,b; Brennecke et al. 2007; Gunawardane et al. 2007; Ghildiyal and Zamore 2009; Siomi et al. 2011). Inactivation of the piRNA pathway leads to transposon derepression and a failure of germ cell development that has been correlated with DNA damage and genome instability.

piRNAs are derived from both discrete noncoding RNA loci rich in transposon content (piRNA clusters) and the transcripts of active transposons (Aravin et al. 2007a; Brennecke et al. 2007; Gunawardane et al. 2007; Ghildiyal and Zamore 2009; Malone et al. 2009; Siomi et al. 2011). This occurs via several distinct biogenesis mechanisms. Primary biogenesis usually refers to the production of piRNAs from clusters by endonucleolytic cleavage of long noncoding RNAs containing assemblies of up to hundreds

Corresponding author: greg.hannon@cruk.cam.ac.uk Article is online at http://www.genesdev.org/cgi/doi/10.1101/gad.284927. 116. of kilobases of fragmented transposon sequences. Secondary biogenesis comprises the "ping-pong" cycle, in which RNA cleavage by a PIWI protein initiates the production of a new piRNA with its $5^{\prime}$ end at the cleavage site. These sense and antisense piRNAs, derived from both clusters and transposon mRNAs, have characteristic sequence relationships and occupy Ago3 and Aub, respectively, in flies (Brennecke et al. 2007; Gunawardane et al. 2007). Cleavage by Ago3 can also initiate the production of phased "trail" piRNAs, which mainly bind Piwi in Drosophila (Han et al. 2015; Homolka et al. 2015; Mohn et al. 2015; Senti et al. 2015; Wang et al. 2015b).

Once armed with piRNAs, PIWI family proteins recognize and silence complementary targets both transcriptionally and post-transcriptionally. The ping-pong cycle embodies a mechanism of post-transcriptional silencing that consumes transposon mRNAs. Piwi and its presumed mouse ortholog, MIWI2, are nuclear and likely act by recognition of nascent transcripts at target loci.

(C) 2016 Fagegaltier et al. This article is distributed exclusively by Cold Spring Harbor Laboratory Press for the first six months after the full-issue publication date (see http://genesdev.cshlp.org/site/misc/terms.xhtml). After six months, it is available under a Creative Commons License (Attribution-NonCommercial 4.0 International), as described at http:// creativecommons.org/licenses/by-nc/4.0/. 
Nuclear PIWI proteins, along with cofactors (Asterix and Panoramix in flies), recruit histone-modifying enzymes, including deacetylases and methyltransferases, to establish a chromatin signature correlated with transcriptional repression (Dönertas et al. 2013; Muerdter et al. 2013; Ohtani et al. 2013; Rozhkov et al. 2013; Sienski et al. 2015; Yu et al. 2015).

In adult flies, the piRNA pathway is restricted to reproductive tissues. In female germ cells, a fully elaborated pathway operates with priming by inheritance of maternal piRNAs, a robust ping-pong cycle, primary biogenesis, and the production of TGS-inducing trail piRNAs (Brennecke et al. 2007; Gunawardane et al. 2007; Ghildiyal and Zamore 2009; Siomi et al. 2011; Han et al. 2015; Homolka et al. 2015; Mohn et al. 2015; Senti et al. 2015; Wang et al. 2015b; Czech and Hannon 2016). A simplified pathway operates in the somatic follicle cells that surround and support the developing female germ cells (Malone et al. 2009; Haase et al. 2010; Olivieri et al. 2010; Saito et al. 2010). Here, primary biogenesis loads the only expressed PIWI protein, Piwi, which in turn silences transposons by repressing transcription. A largely nonoverlapping set of generative loci feeds piRNA production in germline and follicle cells (Malone et al. 2009). This correlates with the tropisms of the transposons that they target, leading to not only germline or somatic piRNA clusters but also annotation of transposons as largely soma-biased, largely germline-biased, or intermediate elements that are targeted in both compartments. A subset of piRNAs has also been implicated in the regulation of protein-coding genes in both flies and mammals (Saito et al. 2009; Robine et al. 2009). In particular, when biogenesis from bona fide piRNA clusters is disrupted, ectopic piRNAs are produced from a broad spectrum of protein-coding genes in fly ovaries (Han et al. 2015; Mohn et al. 2015).

In mammals, the piRNA pathway is also largely restricted to reproductive tissues. However, a number of reports have demonstrated the expression of mRNAs encoding components of the piRNA pathway in somatic cell types (Ross et al. 2014; Chu et al. 2015). In particular, mRNAs for PIWI family proteins are often detected in stem cell populations, although there is still little information on whether these proteins are loaded with piRNAs or whether they perform a function in those cells. In this regard, mice lacking PIWI proteins, even in combination, show obvious phenotypes only in the germline (Ross et al. 2014; A Girard and GJ Hannon, unpubl.). A significant amount of literature has also developed around the expression of PIWI family proteins in cancer (Hashim et al. 2014; Ross et al. 2014; Chu et al. 2015).

For $>25$ years, it has been apparent that a diversity of cancers reactivate the expression of genes normally restricted to germ cells (Simpson et al. 2005). These have been widely proposed as antigens to selectively target the immune system to cancer cells; however, a paucity of studies has examined whether cancer/testis antigens (CTAs) are simply markers of cancer or whether they play any functional roles. Among the CTAs, PIWI proteins and other components of the piRNA pathway have been detected in a number of different tumor types, including those of the breast, colon, and pancreas (for review, see Ross et al. 2014). In bladder and breast cancer, 100 different loci produce small RNAs with features reminiscent of piRNAs (Hashim et al. 2014; Chu et al. 2015). However, their physical association with Piwi was not demonstrated and their biological function was not examined. An analogous situation in which germline genes are re-expressed in tumors may also exist in flies.

Lethal (3) malignant brain tumor $[1(3) \mathrm{mbt}]$ is an insulator-binding protein whose loss causes the development of brain neoplasms in flies (Janic et al. 2010). 1(3) mbt is also important for germline development (Richter et al. 2011). This protein regulates multiple targets of the Salvador-Warts-Hippo (SWH) pathway, which tunes the balance of proliferation and apoptosis to determine organ size (Cook 2015). The membrane proteins Expanded (Ex) and Fat control a protein complex containing the Hippo (Hpo) and Warts (Wts) kinases. These phosphorylate a transcriptional activator, Yorkie (Yki), causing its cytoplasmic sequestration. In the nucleus, Yki normally cooperates with other transcription factors to promote the expression of genes that enhance growth (e.g., cyclin E) and survival (e.g., DIAP-1 and bantam). A causal role for the altered expression of SWH pathway targets in 1(3) $m b t$ mutant tumors is supported by studies in which mutation of bantam or yki or enforced expression of Ex suppressed tumorigenesis (Richter et al. 2011; Blanchard et al. 2014; Zhang et al. 2015).

As in many human neoplasms, Piwi becomes re-expressed in 1(3)mbt mutant fly tumors (Janic et al. 2010). This could be due to the fact that germline transcription factors, which are targets of $1(3) \mathrm{mbt}$, also become activated (Richter et al. 2011; Meier et al. 2012; Blanchard et al. 2014; Zhang et al. 2015). These include LINT, which has been implicated in the regulation of Piwi expression, as well as vasa (vas), bag of marbles (bam), and benign gonial cell neoplasm ( $\mathrm{ggcn})$, all of which play important roles in the regulation of germ cell division. Of note, the loss of Piwi suppressed tumorigenesis in $1(3) \mathrm{mbt}$ mutants, supporting the hypothesis that its increased expression in these mutants might have functional importance (Janic et al. 2010).

\section{Results}

Alterations of Ras and Wts induce expression of piRNA pathway components

We sought to address whether oncogenic events that renew germline gene expression could reactivate a functional piRNA pathway and whether this might contribute to tumorigenesis. We focused initially on the SWH pathway, as it had been implicated previously in inappropriate Piwi expression in Drosophila brain tumors, and on alterations in Ras pathway signaling, which contribute to at least $30 \%$ of human cancers.

We altered the SWH signaling pathway in developing flies using RNAi against the regulatory kinase Wts (Wts$R N A i)$ and overexpressed the oncogenic form of the 
Ras85D protein ( $\operatorname{Ras}^{\mathrm{V} 12}$ ). To avoid Ras ${ }^{\mathrm{V} 12}$-induced embryonic lethality, we generated clones that express Ras ${ }^{\mathrm{V} 12}$, silence $W t s$, or do both in combination (Wts-RNAi;Ras ${ }^{\text {V12) }}$ in larvae using the ubiquitous Act5C-GAL4 driver. We assessed Piwi expression 3-5 d later in larval wing discs. All Ras $^{V 12}$,Wts-RNAi, and Wts-RNAi;Ras ${ }^{\mathrm{V} 12}$ clones showed ectopic Piwi expression by immunofluorescence (Fig. 1). Thus, experimental manipulation of conserved oncogene and tumor suppressor networks can reactivate Piwi expression in somatic lineages.

\section{Manipulation of Ras and SWH signaling is required to maintain Piwi expression in cell culture}

The necessity of activating Ras only in a minority of clones in developing flies limited further analysis in this system. We therefore established primary cell cultures from embryos with Ras activation (Dequéant et al. 2015), SWH pathway inactivation, Wts-RNAi, or the combined alterations (Simcox et al. 2008). These lines could be grown continuously in culture for $>100$ passages, and, upon transplantation in vivo, Ras ${ }^{\mathrm{V} 12}$ and Wts-RNAi; Ras $^{\mathrm{V} 12}$ formed tumors in flies (Wts-RNAi alone was not tested) (Simcox et al. 2008; data not shown).

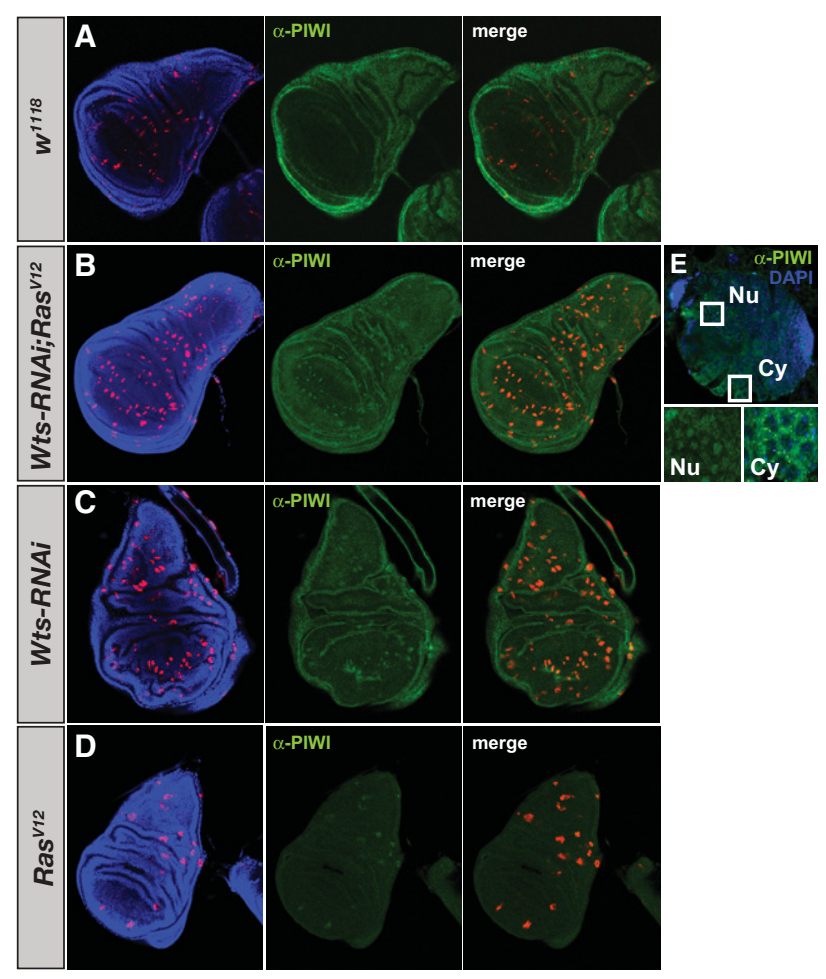

Figure 1. Wts-RNAi and activated Ras ${ }^{\mathrm{V} 12}$ induce ectopic expression of Piwi in wing discs. (A) hsFLP,Act-Gal4>UAS-RFP control clones (red) mark the nucleus. Wts-RNAi; Ras ${ }^{V 12}(B)$, Wts-RNAi $(C)$, and $\operatorname{Ras}^{V 12}(D)$ wing disc clones express Piwi. (E) Cells with nuclear endogenous Piwi (left; Nu) and cytoplasmic PIWI (right; Cy) foci coexist in the developing female Wts-RNAi; Ras $^{12}$ larval gonad, stained in the same well as discs. (Blue) DAPI; (red) UAS-RFP clones; (green) a-Piwi. (Left panels) DAPI/ RFP merge. (Right panels) RFP/a-Piwi merge.
Ras $^{\mathrm{V} 12}$ cells rapidly lost Piwi expression in vitro (Fig. 2A; Supplemental Fig. S1); by passages 3-5, Piwi protein became undetectable. Similarly, in Wts-RNAi cells, Piwi was not expressed strongly, if at all (Supplemental Fig. S2A). This was also true in cells derived from Warts or Hippo mutant embryos (Supplemental Fig. S2A). In contrast, Wts-RNAi;Ras ${ }^{\mathrm{V} 12}$ cells (referred to here as WRR-1 cells) maintained robust Piwi expression for $>100$ passages (Fig. 2A). This was a consistent property, as five independently derived lines showed similar characteristics (Supplemental Fig. S3). Notably, Piwi protein was nuclear in these cells. Previous studies have indicated that nuclear PIWI family proteins must be loaded with piRNAs to maintain both stability and nuclear localization. This strongly implied a broader activation of piRNA pathway components and raised important questions about the nature of the small RNAs that might be loaded into Piwi in WRR-1 cells.

\section{piRNA pathway genes are expressed in WRR-1 cells}

To examine more broadly the spectrum of germline genes and, more specifically, piRNA pathway components that are re-expressed in WRR-1 cells, we profiled their transcriptomes. This was compared with the transcriptomes of two activated Ras cell lines, ovaries, and an ovarian somatic sheet (OSS) cell line that models ovarian follicle cells. WRR-1 cells expressed germ cell-specific genes to a greater degree than Ras ${ }^{\mathrm{V} 12}$ cells (Fig. 2B; Supplemental Fig. S4). Notably, unlike OSS cells, WRR-1 expressed all three PIWI family members (Fig. 2B), and, like Piwi, Aub and Ago3 expression could be validated also at the protein level (Supplemental Fig. S2B,C). Although much stronger than in Ras ${ }^{\mathrm{V} 12}$ cells, Piwi expression was somewhat lower in WRR-1 than in OSS cells (Fig. 2C).

Many elements of the piRNA pathway have been annotated, with particularly complete compendia recently emerging from large-scale screens in Drosophila germ and follicle cells (Czech et al. 2013; Handler et al. 2013; Muerdter et al. 2013). Like PIWI family proteins, many piRNA pathway genes are also re-expressed in WRR-1 cells (Fig. 2B). Notably, increased RNA expression is observed for the established factors armi, mino, vret, shu, del, and panx as well as the strong screen hits CG14438, CG13741, and CG12721. More moderate increases are seen for zuc, GASZ, and arx (Fig. 2B; Supplemental Fig. S4C). Several important piRNA pathway components, including rhi, cuff, qin, tej, and vas, show lower levels of expression in WRR-1; however, for many of these components, similarly low levels are observed in ovaries, where their functional importance is unquestioned.

Overall, the transcriptome of WRR-1 cells resembles that of somatic cells with a deficient SWH pathway more than typical germ cells. One striking particularity of WRR-1 cells is their male signature, illustrated by high levels of the male isoforms of $d s x$, the master regulators of sex determination (Supplemental Fig. S4A), and the expression of a Y-linked gene $(M s t 77 Y-16 \Psi)$ and repeats \{Suppressor of Stellate [Su(Ste)]\} (Supplemental Fig. S5A; Aravin et al. 2001; Robinett et al. 2010). Karyotypes 
Fagegaltier et al.

A

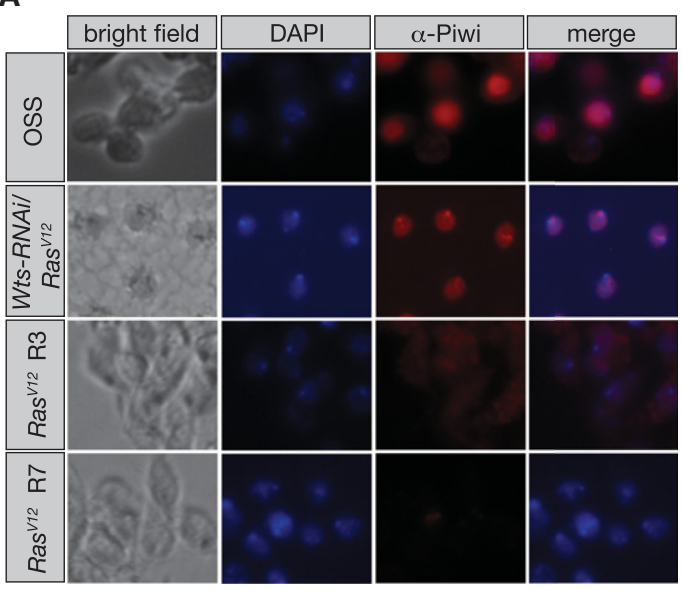

C

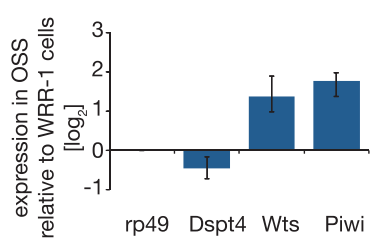

E

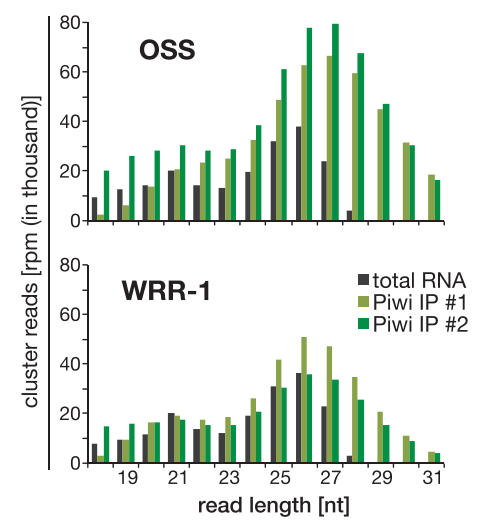

F

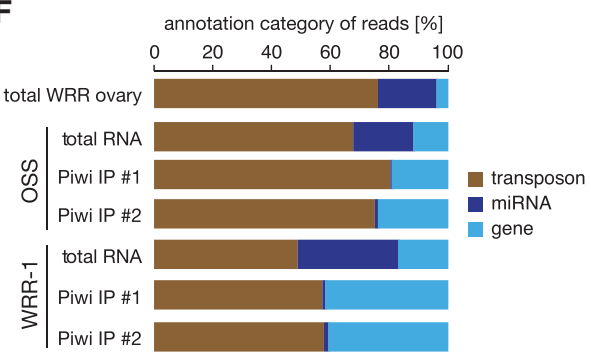

B

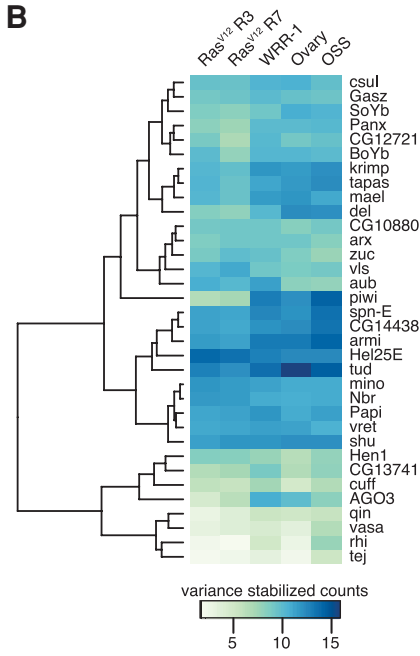

D

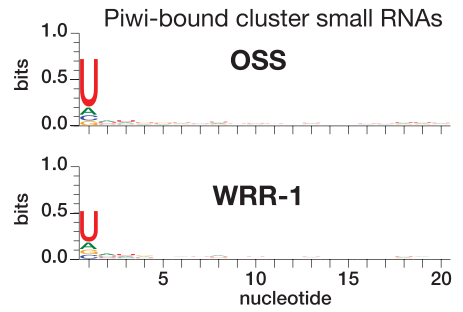

G

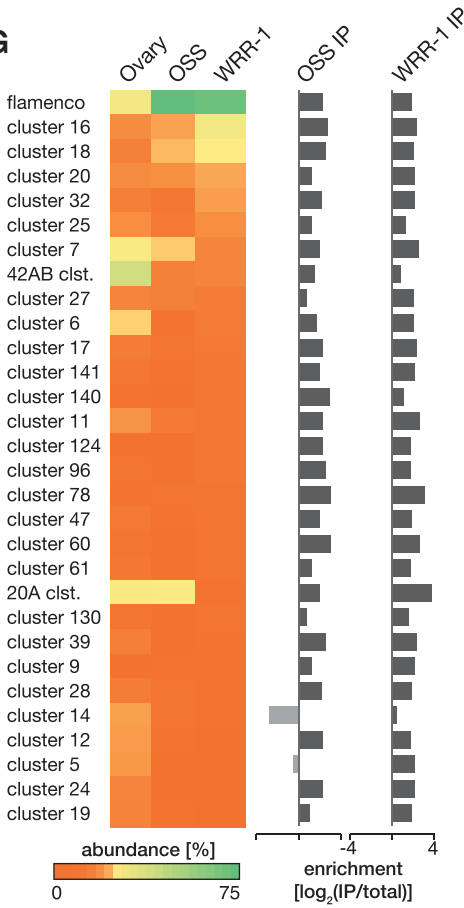

Figure 2. piRNA machinery and Piwi-bound piRNAs in WRR-1 cells. (A) Piwi localizes to the nucleus of ovarian somatic sheet (OSS) and WRR-1 cells and is undetectable in two Ras ${ }^{\mathrm{V} 12}$ lines (R3 and R7). (Blue) DAPI; (red) a-Piwi. (B) Transcript levels of piRNA pathway components in Ras ${ }^{\mathrm{V} 12}$ (R3 and R7), WRR-1, ovary, and OSS cells. (C) Piwi mRNA levels are shown in OSS cells compared with WRR-1 cells by quantitative PCR (qPCR). Dspt4 served as a control. (D) Piwi-bound piRNAs originating from clusters in WRR-1 cells show a 5' U bias, similar to OSS cells. (E) Genomic clusters generate primarily 23- to 29-nt piRNAs associated with Piwi (Piwi immunoprecipitation [IP] $\# 1$ and \#2). (F) Genomic distribution of small RNAs cloned from whole (total) and Piwi-bound (immunoprecipitation) fractions in OSS and WRR-1 cells and in control ovaries. (G) piRNA abundance at clusters in WRR-1, OSS cells, and ovaries. Clusters are ranked by piRNA abundance in WRR-1 cells. piRNAs from genomic clusters associate with Piwi in immunoprecipitations from OSS and WRR-1, shown as enrichment $\left[\log _{2}(\mathrm{RPM}\right.$ IP/total)]. 
confirm the presence of a Y chromosome (data not shown). Along with the three PIWI family proteins, WRR-1 cells express mael (Supplemental Fig. S4B), vas, and nos (Supplemental Fig. S4C), all characteristic of germ cells. WRR- 1 cells also express most of the germline genes inappropriately expressed in 1(3) mbt brains (e.g., the germlinespecific ThioredoxinT [TrxT]) (Supplemental Fig. S4C; Parisi et al. 2010). We also observed important transcriptional regulators of the male germline such as $n h t, s a$, tumorous testis (tut), and vis that control-with aly, topi, and comr - meiotic cell cycle progression and cellular differentiation in spermatocytes (Perezgasga et al. 2004), together with transcription factors expressed solely in the early embryo. These patterns distinguish WRR-1 cells from activated Ras ${ }^{\mathrm{V} 12}$ cells and either the ovarian or testis germ cells proper (Fig. 2B; Supplemental Fig. S4). Together, our results point at a male somatic origin of WRR-1 cells in which germline genes are re-expressed owing to a deficient SWH pathway and constitutively activated Ras (Supplemental Fig. S4D).

WRR-1 cells produce bona fide piRNAs, which are loaded into Piwi

In the absence of piRNAs, Piwi localizes to the cytoplasm of OSS cells (Saito et al. 2010). The nuclear localization of Piwi in WRR-1 cells strongly implies its association with small RNAs. To probe this possibility, we immunoaffinity-purified Piwi and examined its associated small RNAs by $5^{\prime}$ end labeling. Piwi was efficiently recovered from WRR-1 or OSS cells but not from cells mutant for Wts alone $\left(w t s^{M g h 1}\right)$ or expressing activated Ras (Supplemental Fig. S5B; data not shown). In Piwi immunoprecipitates from WRR-1, we detected a population of bound small RNAs with a strong $5^{\prime} \mathrm{U}$ bias (Fig. 2D), a signature characteristic of piRNAs. These were $25-30 \mathrm{nt}$ and appeared very similar to those recovered in Piwi isolations from OSS cells (Fig. 2E; Supplemental Fig. S5C).

Total small RNA populations were also cloned from OSS and WRR-1 cells and, as a control, ovaries. These, along with those recovered from Piwi complexes, were sequenced and classified as repeat-derived, of genic origin, or microRNAs (miRNAs) (Fig. 2F). Even total small RNA populations were enriched for transposon-related reads in both OSS and WRR-1. In Piwi immunoprecipitates from either cell line, the fraction of miRNA reads was substantially depleted, while transposon-related and genic reads were increased.

Piwi-bound small RNAs originated from well-annotated piRNA clusters in both OSS and WRR-1 cells (Fig. 2G; Malone et al. 2009). As expected, in total RNA from OSS cells, flamenco is the most predominant cluster, contributing $76 \%$ of the mapping small RNA reads in the piRNA size range (23-29 nt). Cluster 20A, the other unistrand cluster, also contributes significantly, as does cluster 7 to a lesser degree (Malone et al. 2009). In WRR-1 cells, flamenco is again dominant, accounting for $71 \%$ of putative piRNA reads. Clusters 16 and 18 also contribute. In contrast, $42 \mathrm{AB}$ is the predominant cluster in ovaries (Malone et al. 2009). piRNAs mapping to the vast majority of anno- tated clusters were enriched in Piwi immunoprecipitates irrespective of their relative contribution in the total. It should be noted that piRNA clusters are polymorphic among strains and that assignment was made to clusters in the reference genome. Thus, particularly those clusters with minor contributions might have attracted mappers that, in the relevant strain, should actually be assigned to a different genomic locus. Overall, these data suggest that, along with reactivating the expression of germline protein-coding genes, WRR-1 cells reactivate cluster expression and a sufficient cohort of piRNA biogenesis factors to produce bona fide piRNAs that are mainly flamenco-derived.

\section{A primary piRNA pathway in WRR-1 cells}

We examined the requirements for piRNA production from annotated clusters by systematically depleting critical components of the primary and secondary pathways in WRR-1 cells. Silencing of Zuc or Armi had a strong impact on the detection of nuclear Piwi protein, consistent with results from OSS cells, showing that both of these proteins are important for loading Piwi via the primary piRNA pathway (Fig. 3A). Silencing of Aub or Ago3 had little impact on Piwi localization or its associated small RNA populations, suggesting that, in WRR-1 cells, cleavage-directed initiation of trail piRNA production is not prominent.

Small RNA populations in WRR-1 cells treated with RNAi against primary biogenesis components changed in a manner similar to that observed for Piwi knockdown (Fig. 3B). The fraction of reads mapping to transposons decreased, while the relative abundance of annotated miRNAs increased. Knockdown of Aub or Ago3 showed little deviation from the control. Taking into account only the piRNA fraction (23-29 nt) derived from annotated clusters, similar results are obtained (Fig. 3C). Knockdown of Piwi, Armi, or Zuc reduces steady-state piRNA levels to a very similar degree. This is true at not only well-represented clusters, such as flamenco and clusters 16 and 18 , but also clusters that contribute much less prominently to the overall pool. Knockdown of Ago3 or Aub had insignificant impacts, except for one outlier, where piRNA levels from cluster 12 increased upon knockdown. Limited ping-pong pairs $(>10,000$-fold fewer than found in ovaries) are formed at germline cluster 42AB. This agrees with its low expression in male WRR1 cells, the poor expression of Aub and Ago3, and their limited impact on piRNA population. Altogether, these data indicate that piRNAs arise in WRR-1 cells via a primary biogenesis pathway that loads predominantly Piwi.

\section{Su(Ste) repeats in WRR-1 cells}

The Stellate locus on the X chromosome is silenced posttranscriptionally in spermatocytes by mechanisms involving piRNAs produced from the Y-linked Su(Ste) repeats (Aravin et al. 2004). Aub, Ago3, Zuc, Armi, and Krimper take part in Stellate silencing (Nagao et al. 2010). These factors localize to the nuage and in 

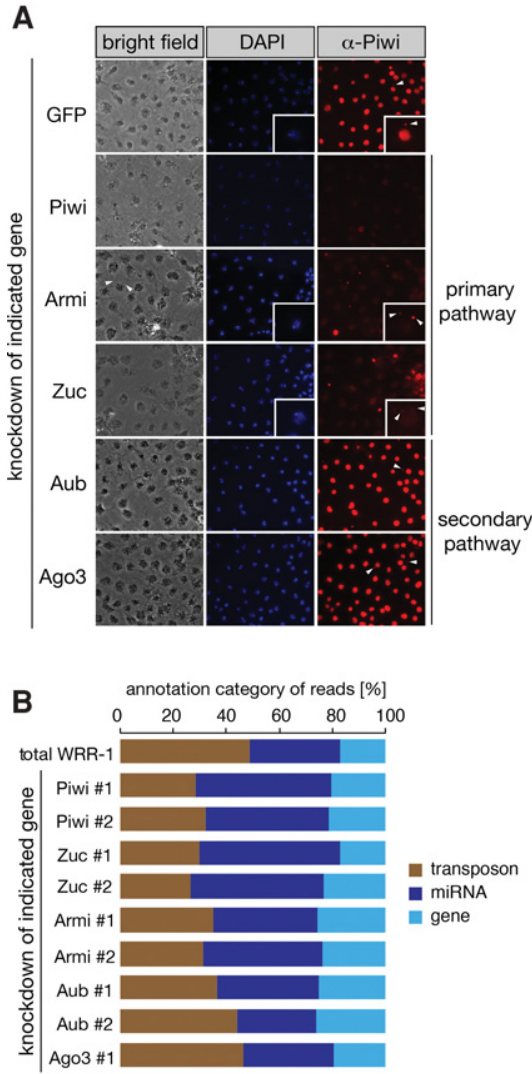

C
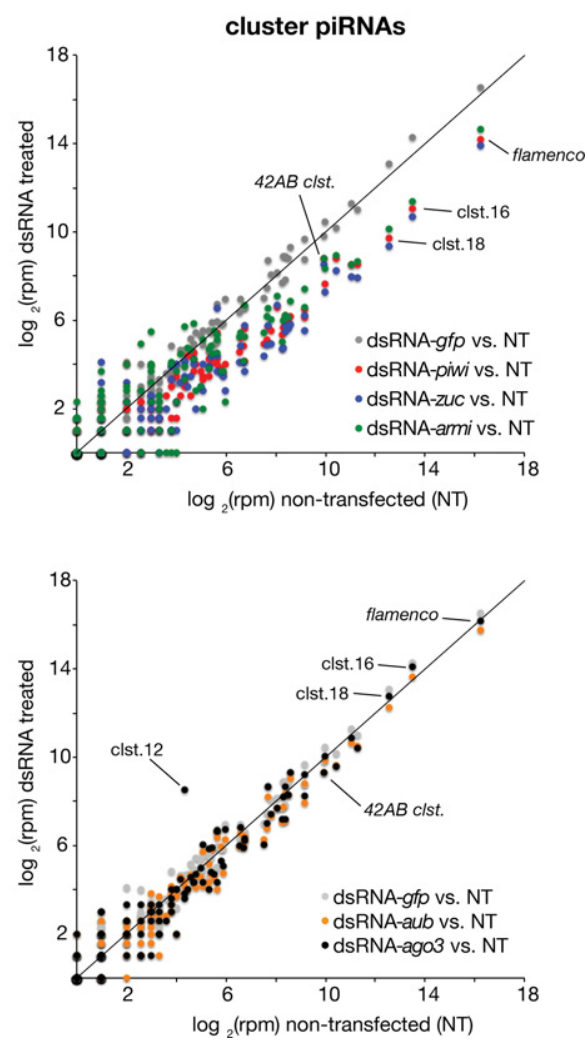

Figure 3. The effects of depleting piRNA pathway components. (A) Piwi staining in the indicated knockdown cells. Immunofluorescence was performed $5 \mathrm{~d}$ after transfection of dsRNAs against each indicated gene. Piwi protein is undetectable in most Piwi-depleted cells and aggregates in cytoplasmic foci in Zuc and Armi knockdowns (insets, arrowheads). (Blue) DAPI; (red) aPiwi. (B) Piwi, Armi, and Zuc knockdowns impair piRNA production; Aub or Ago3 depletion has no effect. (C, top panel) Piwi, Zuc, and Armi knockdowns decrease piRNA levels at most clusters, including flamenco. (Bottom panel) Depletion of Aub or Ago3 shows little to no effect on piRNA production at clusters. Depletion of GFP (control) has no effect. organelles at the periphery of spermatocyte nuclei (Kibanov et al. 2011). Piwi is largely absent from spermatocytes. As a result, most Stellate piRNAs come from complementary (or antisense) Su(Ste) repeat transcripts and are bound to Aub (Nagao et al. 2010). As fewer piRNAs bound to Ago3 are antisense Su(Ste), it was suggested that Aub and Ago3 do not engage in ping-pong in testis, although they cooperate to regulate $\mathrm{Su}(\mathrm{Ste})$ transcripts. Only a few sense piRNAs can be found in Piwi immunoprecipitates in whole testis, consistent with its very low level of expression.

WRR-1 cells are male and contain a Y chromosome. These cells also produce piRNAs matching Su(Ste) repeats, which are testis-specific and have not been observed previously in a context that also produces femalespecific piRNAs (Supplemental Fig. S5A). We found both sense and, more prominently, antisense piRNAs to Su (Ste) transcripts in WRR-1 cells. Both populations are found in Piwi immunoprecipitates and are reduced in Piwi knockdown cells. This is unexpected, as these small RNAs are normally associated with Aub in testis, and both Aub mRNA and protein are present in WRR-1. This implies that the machinery needed for loading these and perhaps other piRNAs into Aub is not substantially active in WRR-1 or that Aub protein levels are simply low in these cells. Of note, WRR-1 cells fail to reactivate $\mathrm{X}$ upstream (Fig. 2G, 20A cluster), which produces abundant piRNAs in both testis and ovaries (Brennecke et al. 2007; Nagao et al. 2010).
piRNA-mediated transposon silencing in WRR-1 cells

piRNAs function in reproductive tissues to repress transposon expression and guard the genome of developing germ cells against damage. In Drosophila, piRNAs act in both the germ cells themselves and the surrounding somatic cell layer that supports the developing germline. A distinct but partially overlapping set of clusters generates piRNAs in each of these compartments, directing the pathway toward transposons active in that compartment. This results in the annotation of transposons as being germline-biased, soma-biased, or intermediate (i.e., targeted in both) (Brennecke et al. 2007; Malone et al. 2009). Sorting transposons by this annotation and comparing relative targeting by small RNAs revealed that, in WRR-1 cells, the most highly targeted were soma-biased and intermediate elements (Fig. 4A). Similar results were obtained for Piwi-bound piRNA populations. This is consistent with flamenco being the major contributor to piRNA populations just as in OSS cells. We observed a slight increase in the targeting of germline-biased elements in WRR-1 as compared with OSS, again consistent with the activation of piRNA production, albeit at low levels, from a broad spectrum of germline clusters in WRR-1. As it was observed from a cluster-centric perspective, piRNAs against the majority of elements-and certainly the most targeted-were diminished in knockdowns of Piwi, Zuc, and Armi, while most failed to respond to silencing of Aub or Ago3 (Fig. 4B). As expected, 

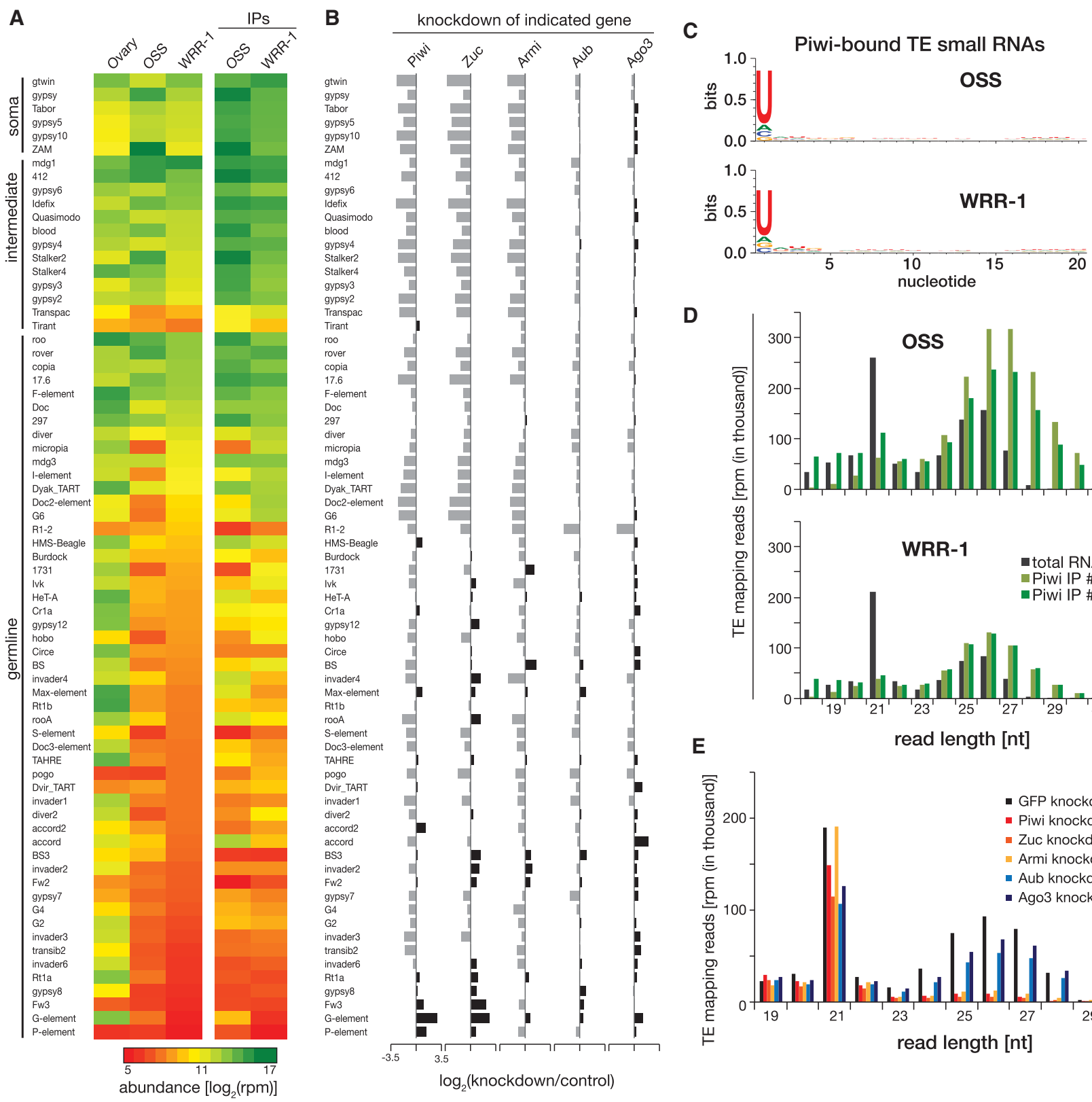

D

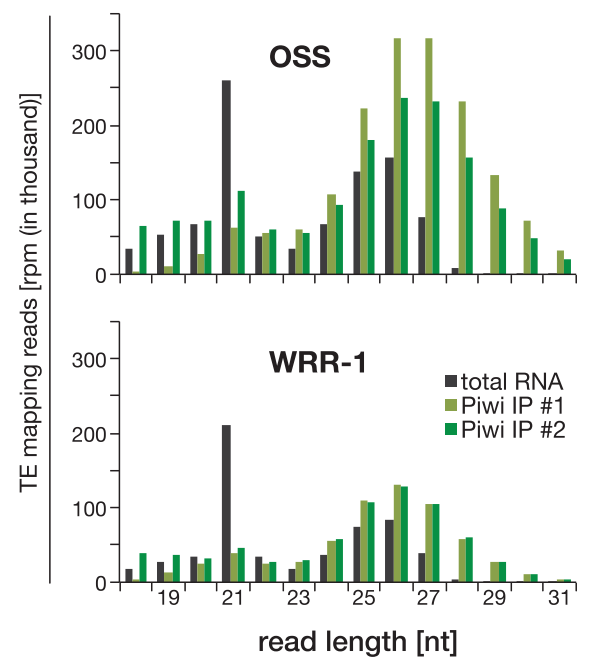

E

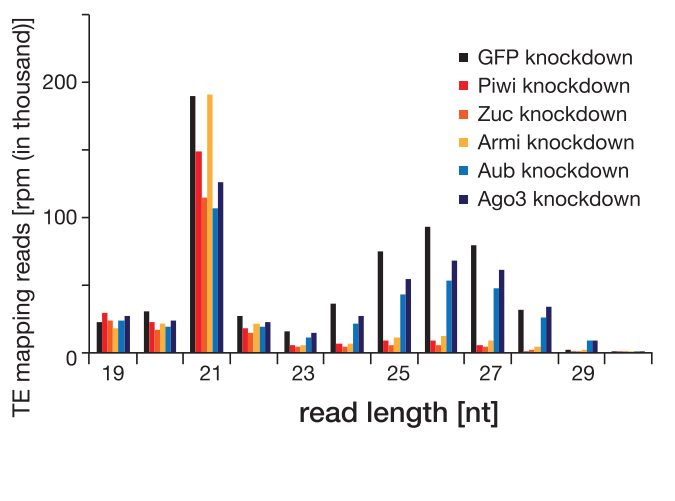

Figure 4. The primary pathway generates piRNAs matching a broad spectrum of transposons. $(A)$ The most abundant piRNAs matching to transposable elements (TEs) in WRR-1 cells correspond primarily to somatic and intermediate transposons (gypsy elements, idefix, or $Z A M)$, consistent with their production from the flamenco locus. These piRNAs are associated with Piwi. (Bottom) Fewer piRNAs are derived from germline-specific transposons. (B) piRNA levels decrease in Piwi, Zuc, or Armi knockdowns but remain largely unaltered upon depletion of Aub or Ago3. $(C, D)$ piRNAs matching consensus TEs present a $5^{\prime} \mathrm{U}$ bias $(C)$ and are selectively bound to Piwi $(D)$ in WRR-1 cells, in contrast to 21-nt endo-siRNAs originating from TEs. (E) Piwi, Zuc, or Armi depletion selectively abolishes the production of 23- to 29-nt TE-matching piRNAs.

small RNAs targeting transposons showed a strong $5^{\prime} \mathrm{U}$ bias (Fig. 4C), and, in both OSS and WRR-1 cells, their size distribution was consistent with the production of both piRNAs and endo-siRNAs targeting transposons (Fig. 4D). Notably, only those of the size class corresponding to piRNAs responded to loss of Piwi or primary biogenesis factors (Fig. 4E).

To determine whether piRNAs matching transposons had any biological impact in WRR-1, we examined RNA sequencing (RNA-seq) data from cells in which piRNA pathway components had been silenced. RNAi directed against Piwi, Armi, or Zuc all generally increased the expression of a broad spectrum of transposons as compared with control knockdowns (Fig. 5). This behavior was consistent across the germline-biased, soma-biased, and intermediate elements, as it might be predicted from the broader spectrum of clusters that are active in WRR-1 as compared with OSS cells. Knockdown of Aub or Ago3 

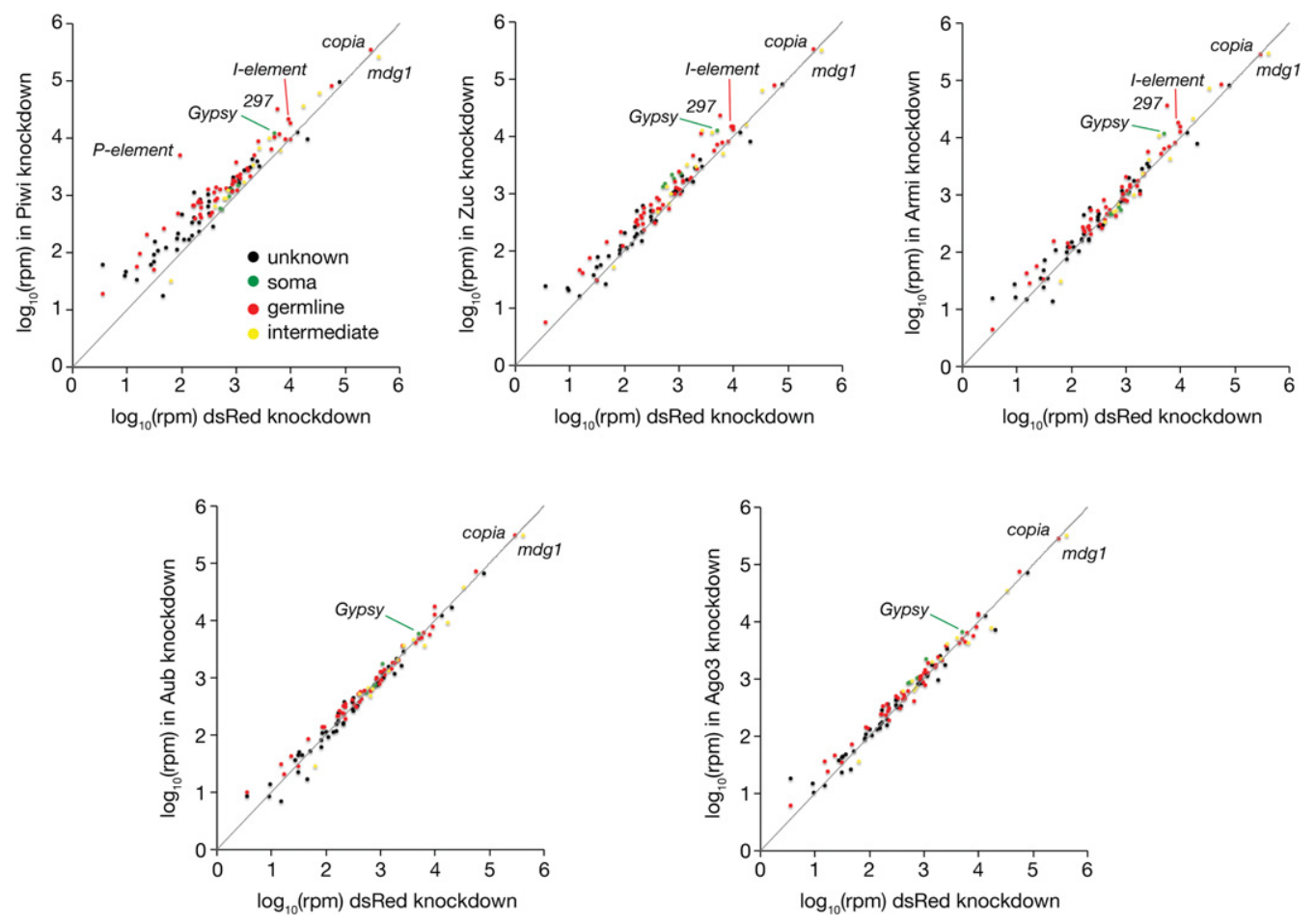

Figure 5. Transposons are regulated by the primary piRNA machinery. Transposon transcripts are up-regulated in Piwi, Zuc, and Armi knockdowns and remain unchanged in Aub and Ago3 knockdowns. Colored dots represent the expression of a transposon as $\log _{10}(\mathrm{RPM})$ and its somatic or germline classification.

had little effect, consistent with their lack of impact on piRNA populations matching transposons.

The increase in transposon expression upon inactivation of the piRNA pathway in WRR-1 was substantial. Elements across the entire range of baseline expression levels increased up to 10-fold or more (Fig. 5). In general, the elements with the highest baseline expression were somewhat less affected.

\section{The piRNA pathway promotes proliferation of WRR-1 cells}

The piRNA pathway clearly functions in WRR-1 cells to help repress transposon expression. To assess whether loss of the piRNA pathway had any additional phenotypic impact, we measured the growth rates of WRR-1 cells in which Piwi was silenced by RNAi. Such cells showed an $\sim 40 \%$ reduction in EdU labeling, implying a decrease of $\mathrm{S}$-phase cells and, consequently, proliferation rate (a representative experiment is shown in Fig. 6A). This is a substantial impact, and cells in which piRNA pathway activity was compromised would be rapidly lost from a proliferating mixed population.

We imagine several possible mechanisms that could underlie this effect. First, increased expression of transposon mRNAs could result in chronic DNA damage, engaging checkpoint mechanisms that prevent cell division until repair is accomplished. Alternatively, the expression of genes important for proliferation could be impacted by Piwi loss (Fig. 6; Supplemental Tables S1-S8). This could occur through direct or indirect mechanisms. For example, some genes rely on regulatory elements that are donated from closely linked transposons, and their expression could be altered when the piRNA pathway is disrupted. We also noted a substantial fraction of genic piRNAs in association with Piwi in WRR-1 cells, somewhat greater than that observed in OSS cells (Fig. 2F). These could conceivably regulate the expression, for example, of growth inhibitory genes.

We extracted the set of differentially expressed genes that are potentially targeted by piRNAs (Fig. 6B). We required these to have $\geq 100$ uniquely mapping piRNAs per million reads in Piwi immunoprecipitates from WRR-1 cells. This set contained 42 genes whose expression increased upon silencing of Piwi and 22 whose mRNA decreased (more than twofold; false discovery rate [FDR], 0.05) (Supplemental Tables S1, S2). Many of these were also changed upon silencing of Armi or Zuc (Supplemental Tables S3-S8), with 22 genes up-regulated and 12 genes down-regulated in all three knockdowns. While we did not validate that changes in any of these are responsible for the impact of Piwi on the proliferation of WRR-1 cells, there are regulators of cell growth and division among those genes that change expression, although enrichment in proliferation genes in this set does not reach statistical significance. As examples, important signaling molecules become reactivated upon Piwi depletion, such as the ligand and growth factor Pvf1 (Ras-dependent RTK and PDGF/VEGF pathways) and the $P H 4 \alpha P V$ gene that modulates signaling factors and adhesion molecules 

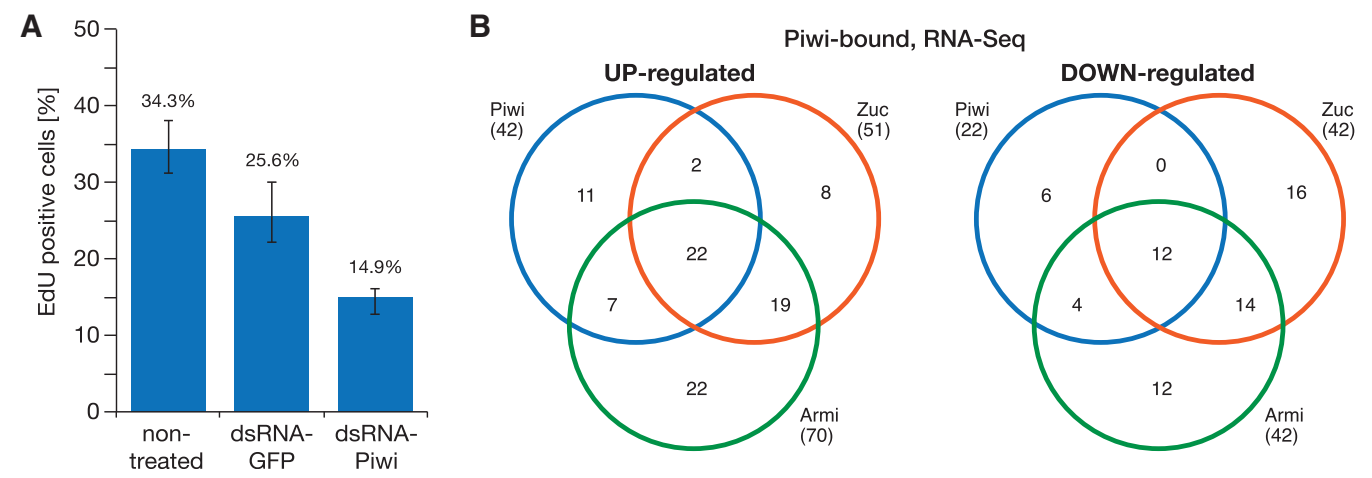

Figure 6. Piwi promotes the growth of WRR-1 cells and affects gene expression programs. (A) Proliferation of WRR-1 cells decreases upon Piwi knockdown, as compared with control (nontransfected) and GFP knockdown cells. A representative EdU pulse-labeling assay is presented as the percentage of EdU-labeled cells in the population detected following a 5-h pulse. $(B)$ One-hundred-fifty-six genes producing piRNAs in WRR-1 cells show susceptibility to depletion of primary piRNA components at the steady-state RNA level (RNA-seq). For 91 piRNA-producing genes, mRNA levels increase more than twofold upon knockdown of Piwi, Zuc, or Armi, including 22 common up-regulated genes. Transcript levels of 64 genes decrease upon depletion of primary components, 12 of which are down-regulated in knockdowns of Piwi, Zuc, and Armi.

during morphogenesis. Also up-regulated are cell cycle (CBP) and cytokinesis (Kif3C, rempA, CG33521, Syn, and kel) proteins. The cytoskeleton protein kelch is important for ovarian nurse cell-to-oocyte transport and protein degradation, a function carried by another up-regulated gene, $S p n 77 B c$, in accessory glands (Hudson et al. 2015). Conversely, down-regulated genes producing piRNAs include BMP signaling molecules (the growth factor Dawdle [Alp23B] and several Gsts) known to control the cell cycle in fly gonads (Wang et al. 2015a). Gsts proteins modulate cell proliferation, cell differentiation, and apoptosis; a potential role for these proteins in DNA damage signaling has been postulated (Laborde 2010).

\section{Discussion}

We showed that a fully functional primary piRNA pathway is reactivated in somatic cells transformed by combined alteration of the SWH tumor suppressor pathway and activation of Ras. Loss of the piRNA pathway reduces the division rate of these cells, demonstrating that it is biologically impactful in this context. In WRR-1 cells, the piRNA pathway relies mainly on Piwi as a recipient for piRNAs produced from a broad spectrum of piRNA clusters, including those that are largely germline-restricted, expressed mainly in somatic follicle cells, and characteristic of either male or female gonads. This translates into a substantive impact on a wide variety of transposons that include virtually all classes of elements.

The primary piRNA pathway is reactivated along with many other germline-biased genes. This may be attributable to the alteration of the SWH pathway, as Piwi and Ago3 become expressed in hyperactive Yki wing disc cells. This suggests that transcription factors controlled by Yki can directly or indirectly contribute to the regulation of germline gene expression programs (Polesello and Tapon 2007; Blanchard et al. 2014; Zhang et al. 2015). Among the reactivated germline genes are also compo- nents of secondary biogenesis pathways, including Aub and Ago3. Knockdown of either of these two PIWI family proteins had only minor effects on piRNA populations despite the fact that some of the reactivated piRNA clusters normally contribute to piRNA populations produced by the ping-pong cycle. This could suggest that some key elements of secondary biogenesis pathways may not have been re-expressed to a sufficient degree in WRR-1 cells.

Piwi clearly impacts transposon repression in WRR-1 cells. Previously reported studies of germline or follicle cells in flies or OSS cells in culture report fold changes within the range observed here in WRR-1 cells. However, for some elements, increases in expression are greater when the piRNA pathway is lost in the context in which it naturally functions (Sienski et al. 2012; Muerdter et al. 2013; Rozhkov et al. 2013). It is notable that somatic tissues in Drosophila normally do not rely on the piRNA pathway to maintain control over transposons, with the exception of follicle cells; neither do many somatically derived cell lines in culture. Whether this is due to heritable silencing of the elements or a general lack of the promoter activity at clusters in somatic contexts is unclear. From the perspective of the element, there is no apparent selective advantage for activity in cells that do not contribute to the next generation. Even in follicle cells, it is thought that the transposons controlled by the piRNA pathway, mainly gypsy family transposons, propagate by transferring new copies to the adjacent developing germline (Kim et al. 1994; Lécher et al. 1997; Song et al. 1997; Malone et al. 2009). In this regard, it is possible that some transposons themselves fall into the category of germline genes that are re-expressed in the face of oncogenic insult. In WRR-1 cells, this might be compensated by the concurrent activation of a piRNA pathway that represses such elements.

Loss of a functional piRNA pathway reduces the fitness of WRR-1 cells. This could be attributable solely to loss of transposon repression, perhaps with accompanying DNA damage. However, recent studies also imply a post- 
transcriptional regulation of mRNAs by the piRNA pathway to control a variety of important biological processes such as gametogenesis, developmental transitions, and sex determination (Ghildiyal and Zamore 2009; Siomi et al. 2011; Czech and Hannon 2016). We did observe many genes changing expression upon loss of piRNA pathway function (Supplemental Tables S1-S8); thus, it is as yet unclear whether the reduction in growth rate that we detected is due solely to transposon expression or whether direct or indirect regulation of genes by the Piwi pathway contributes.

These putative targets contain many genes that have been linked to cancer progression. As an example, Kif3C is a microtubule-associated motor protein whose orthologs are implicated in tumorigenesis and mouse spermiogenesis (Hogeveen and Sassone-Corsi 2006; Liu et al. 2013). Its association to the CREM complex is required for the transcriptional regulation of many genes (Hogeveen and Sassone-Corsi 2006).

We also identified numerous cases in which a transposon insertion correlates with piRNA-mediated control of a gene in cis. INE-1 element insertions lie downstream from the Pvf1 ligand and Kif3C 3' untranslated regions (UTRs), both of which are up-regulated in Piwi, Zuc, and Armi knockdowns. In the case of Kif3C, readthrough transcription overlaps with an actively transcribed INE-1 transposon on the opposite strand. Kif3C becomes upregulated as the transposon becomes derepressed.

Overall, our results suggest that oncogenic transformation can provoke the reactivation of the piRNA pathway in somatic cells and raise the possibility that this might contribute to oncogenesis, at least in our model. While the underlying mechanism by which this occurs has not been clarified, there are numerous possibilities suggested by our analyses so far. Whether the phenomena that we observed in Drosophila has relevance to human cancer will await further study, but the data presented here provide guides to the genetics of the tumor types in which piRNA pathways might become operational and potentially relevant.

\section{Materials and methods}

\section{Cell lines}

Wts-RNAi;Ras ${ }^{V 12}$ (WRR-1), Ras ${ }^{\mathrm{V} 12}$ (R3), Ras ${ }^{\mathrm{V} 12}$ (R7), Wts-RNAi (\#5), Hippo- ${ }^{-}(\# 2)$, wts $^{\text {mgh1 }}$, and WRR-2-5 cell lines were described by Simcox et al. (2008) and Dequéant et al. (2015).

\section{Fly strains}

rs, hsFLP $, y, w^{1118}$;Act5C>CD2>GAL4,UAS-RFP/TM3Sb, UASNLS-GFP, UAS-Ras ${ }^{V 12}$ (a gift from G. Rubin), UAS-Wts-RNAi (Simcox et al. 2008), and UAS-Wts-RNAi;UAS-Ras ${ }^{\text {V12 }}$ stocks were used in this study.

Generation of $\mathrm{Wts}^{-}$and Ras ${ }^{\mathrm{V} 12}$ clones and analysis of ectopic Piwi expression

$r s, h s F L P, y, w^{1118} ; A c t 5 C>C D 2>G A L 4, U A S-R F P / T M 3 S b$ females were crossed to UAS-NLS-GFP or $w^{1118}$ males as a control and to Wts-RNAi;Ras ${ }^{\mathrm{V} 12}$, Wts-RNAi or Ras ${ }^{\mathrm{V} 12}$ males, respectively, and their progeny were raised at $18^{\circ} \mathrm{C}$. Clones were induced in parallel by a 15 - to 20 -min heat shock at $37^{\circ} \mathrm{C}$ of L2 larvae reared at $18^{\circ} \mathrm{C}$. Approximately $120 \mathrm{~h}$ after heat shock, larval imaginal discs, brains, and gonads were dissected out from wandering selected RFP larvae, fixed for $45 \mathrm{~min}$ in $4 \%$ paraformaldehyde, washed in PBS-T (PBS with $0.1 \%$ Tween), and mounted in ProLong Gold with DAPI for direct visualization of RFP clones. For immunofluorescence, dissected tissues were further blocked in $1 \times$ PBS, $2 \%$ BSA, and 5\% normal goat serum and incubated with rabbit anti-Piwi antibody in blocking solution. After PBS$\mathrm{T}$ washes, samples were incubated with FITC donkey antirabbit secondary antibodies, washed, and mounted. Clone visualization and image capture were performed on a LSM-710 confocal microscope.

\section{Immunohistochemistry on cultured cells}

To localize Piwi, Aub, and Ago3 proteins in vivo, cells were grown in eight-well Labteck II chamber tissue culture slides, fixed for $15 \mathrm{~min}$ in $4 \%$ paraformaldehyde, washed in PBS, permeabilized in $1 \times$ PBS $-0.1 \%$ Triton for $10 \mathrm{~min}$, washed in PBS, and blocked for $1 \mathrm{~h}$ in $2 \%$ BSA. Primary antibodies were rabbit antiPiwi, anti-Aub, and anti-Ago3 (Brennecke et al. 2007) and antivasa (Liang et al. 1994). Washes in PBS-T, followed by secondary 594 anti-rabbit incubation in $2 \%$ BSA, were performed before washes in PBS-T and mounting in ProLong Antifade with DAPI. Signal was acquired on a Nikon eclipse Ti-5 fluorescent microscope and QImaging QIClick camera using NIS Elements software.

\section{Piwi-bound small RNA immunoprecipitation}

Two $75-\mathrm{cm}^{2}$ flasks of OSS, wts ${ }^{-}, \mathrm{Ras}^{\mathrm{V} 12}$ (R3), Ras ${ }^{\mathrm{V} 12}$ (R7), and WRR-1 cells at $80 \%$ confluence were rinsed in $1 \times$ PBS, resuspended in $200 \mu \mathrm{L}$ of lysis buffer $(10 \mathrm{mM}$ Hepes at $\mathrm{pH} 7.0,100 \mathrm{mM} \mathrm{KCl}$, $5 \mathrm{mM} \mathrm{MgCl}_{2}, 0.5 \%$ NP- $40,1 \%$ Triton X-100, $10 \%$ glycerol, $2 \mathrm{mM}$ DTT), and lysed for $10 \mathrm{~min}$ on ice. After removing debris, the supernatant was incubated with $300 \mu \mathrm{L}$ of NT-2 buffer $(50 \mathrm{mM}$ Tris at $\mathrm{pH} 7.4,150 \mathrm{mM} \mathrm{NaCl}, 1 \mathrm{mM} \mathrm{MgCl} 2,0.05 \% \mathrm{NP} 40,1 \mathrm{mM} \mathrm{DTT})$ and anti-Piwi antibody overnight at $4{ }^{\circ} \mathrm{C}$. Piwi complexes were bound to $40 \mu \mathrm{L}$ of protein A-agarose beads (Sigma) preabsorbed in $5 \%$ BSA and $1 \times$ NT-2 and equilibrated in NT-2 buffer. After sequential washes in NT-2 containing $150 \mathrm{mM}, 300 \mathrm{mM}$, and $500 \mathrm{mM} \mathrm{NaCl}$, complexes were treated with Proteinase $\mathrm{K}$ for 1 $\mathrm{h}$ at $60^{\circ} \mathrm{C}$. Piwi-bound small RNAs were extracted with phenolchloroform and precipitated. The size of Piwi-bound small RNAs was assessed by treating one-tenth of the small RNA fractions with CIP in New England Biolabs buffer 3 for $1 \mathrm{~h}$ at $37^{\circ} \mathrm{C}$ followed by phenol-chloroform extraction and $5^{\prime}$ end labeling with PNK (New England Biolabs) and $\gamma$-P32-ATP at $6000 \mathrm{Ci} / \mathrm{mmol}$ for $1 \mathrm{~h}$ at $37^{\circ} \mathrm{C}$. Labeled small RNAs were loaded onto a $15 \%$ PAGE, 7 $M$ urea, and $1 \times$ TBE denaturing gel in RNase-free gel loading buffer II (Ambion), and their size was captured on a phosphoimager.

\section{Knockdowns in cultured cells}

Templates for Piwi, Armi, Zuc, Aub, Ago3, GFP, and dsRED dsRNAs were generated by reverse transcription with oligo-d $(\mathrm{T})_{20}$ primers followed by RNase $\mathrm{H}$ treatment and PCR or direct PCR reactions (Supplemental Table S9). dsRNAs were synthesized using the MEGAscript T7 kit (Ambion) following the manufacturer's instructions. Knockdowns were performed in six-well plates containing $60 \%-70 \%$ confluent WRR-1 cells by transfecting $8 \mu \mathrm{g}$ of dsRNA per well using Effectene (Qiagen) according to 
the manufacturer's instructions. Cells were collected $5 \mathrm{~d}$ after transfection, and knockdown was verified by Western blot and/ or immunohistochemistry. Total RNA was extracted in TRIzol in biological replicates for RNA-seq libraries and small RNA cloning.

\section{RNA sample preparation}

Washed cells were quickly frozen in TRIzol (Invitrogen), and RNA was extracted using an adapted protocol optimized for efficient recovery of both long and small RNAs. Total RNA extracts were prepared from $25-\mathrm{cm}^{2}$ flasks of WRR-1, Ras ${ }^{\mathrm{V} 12} \mathrm{R} 3$, and R7 cells cultured in Drosophila Schneider cell medium supplemented with $10 \%$ fetal bovine serum and $1 \%$ penicillin-streptomycin solution (Gibco).

\section{RNA-seq library preparation}

Five micrograms of total RNAs was depleted of rRNAs (RiboZero rRNA removal kit [human/mouse/rat], Epicentre). RNA integrity and rRNA depletion efficiency were assessed on a Bioanalyzer (Agilent). Two biological duplicate RNA-seq libraries were prepared starting with 200 ng of rRNA-depleted RNAs following the manufacturer's instructions (ScriptSeq version 2 RNA-seq, Epicentre). Multiplexed libraries were clustered and sequenced on a Hi-Seq 2000 or NextSeq Illumina sequencer.

\section{Small RNA library preparation}

Small RNAs (19-28 nt) were isolated from $25 \mu \mathrm{g}$ of total RNA and cloned by ligating adapters according to Malone et al. (2012). Libraries were clustered and sequenced on a GAIIx Illumina sequencer.

\section{Computational analyses}

Small RNA-seq reads were processed exactly as detailed in Muerdter et al. (2013). Reads $>15 \mathrm{nt}$ in length after adapter trimming that failed to map to viral, tRNA, and miscRNA (rRNA, snoRNA, etc) sequences were mapped uniquely and iteratively with up to two mismatches to the Drosophila melanogaster genome (Berkeley Drosophila Genome Project release 5/dm3) using Bowtie and a custom index (Bowtie version 1.1.0) (Langmead et al. 2009). Reads were assigned to FlyBase transcript annotations (dmel-r5.43) using bedtools. The same set of filtered reads was mapped to University of California at Santa Cruz (UCSC) consensus transposon sequences with up to two mismatches. Reads mapping uniquely were considered for further analysis. We determined read counts using bedtools (Quinlan and Hall 2010) and normalized counts per million reads mapping to the genome.

For gene expression analyses, stranded RNA-seq reads were mapped to the transcriptome and the $\mathrm{dm} 3$ genome using TopHat version 2.0.12 (options: -G dmel-r5.43 -fr - g 10), and uniquely mapping reads were annotated with HTSeq (-stranded option). Two replicates were used for all samples but Ras ${ }^{\mathrm{V} 12}$ (R3), ovary, and OSS samples (one replicate). Differential expression was estimated after filtering out rRNAs in pairwise comparisons using DESeq2 version 1.6.3 (Anders and Huber 2010) and R packages. Differentially expressed genes were considered significant when varying at least twofold with a padj-value of $<0.05$. Transposon reads were mapped to UCSC consensus transposon sequences with Bowtie2 (version 2.2.3) (options: -fr -k 10 -N 1 -X 1000) and normalized to genome mappers as described by $\mathrm{Yu}$ et al. (2015).

\section{Proliferation assay}

Five days after transfection, WRR-1 cells were incubated with EdU for $5 \mathrm{~h}$ and labeled with the Click-iT EdU Alexa fluor $594 \mathrm{im}$ aging kit (Life Technologies) according to the manufacturer's recommendations. Duplicates assays were performed. EdU-labeled and DAPI-stained cells were manually counted from four to 10 frames per assay.

\section{Data repository}

All raw and processed data are available through the National Center for Biotechnology Information under Gene Expression Omnibus accession number GSE83877.

\section{Acknowledgments}

We thank Simon Knott, Osama El Demerdash, and Evan Ernst for help with computational work. We thank the Cold Spring Harbor Laboratory Microscopy Shared Resources for assistance, which are funded in part by Cancer Center Support Grant 5P30CA045508. This work was supported in part by a grant from the STARR Cancer Consortium, grants from the National Institutes of Health (NIH MERIT Award, R37GM062534 to G. J.H.), and a generous gift from Kathryn W. Davis to G.J.H. N.P. and G.J.H. are or were Investigators of the Howard Hughes Medical Institute. Stocks obtained from the Bloomington Drosophila Stock Center (NIH P40OD018537) were used in this study. Cell lines have been deposited by A.S. at the Drosophila Genomics Resource Center (NIH 2P40OD010949-10A1). G.J.H. is supported by Cancer Research UK and is a Wellcome Trust Investigator.

\section{References}

Anders S, Huber W. 2010. Differential expression analysis for sequence count data. Genome Biol 11: R106.

Aravin AA, Naumova NM, Tulin AV, Vagin VV, Rozovsky YM, Gvozdev VA. 2001. Double-stranded RNA-mediated silencing of genomic tandem repeats and transposable elements in the D. melanogaster germline. Curr Biol 11: 1017-1027.

Aravin AA, Klenov MS, Vagin VV, Bantignies F, Cavalli G, Gvozdev VA. 2004. Dissection of a natural RNA silencing process in the Drosophila melanogaster germ line. Mol Cell Biol 24: 6742-6750.

Aravin AA, Hannon GJ, Brennecke J. 2007a. The Piwi-piRNA pathway provides an adaptive defense in the transposon arms race. Science 318: 761-764.

Aravin AA, Sachidanandam R, Girard A, Fejes-Toth K, Hannon GJ. 2007b. Developmentally regulated piRNA clusters implicate MILI in transposon control. Science 316: 744-747.

Blanchard DP, Georlette D, Antoszewski L, Botchan MR. 2014. Chromatin reader L(3)mbt requires the Myb-MuvB/DREAM transcriptional regulatory complex for chromosomal recruitment. Proc Natl Acad Sci 111: E4234-E4243.

Brennecke J, Aravin AA, Stark A, Dus M, Kellis M, Sachidanandam R, Hannon GJ. 2007. Discrete small RNA-generating loci as master regulators of transposon activity in Drosophila. Cell 128: 1089-1103.

Chu H, Hui G, Yuan L, Shi D, Wang Y, Du M, Zhong D, Ma L, Tong N, Qin C, et al. 2015. Identification of novel piRNAs in bladder cancer. Cancer Lett 356: 561-567.

Cook TA. 2015. Hypo- or hyper-hippo: a balancing act with bHLH transcription factors. Dev Cell 32: 133-135. 
Czech B, Hannon GJ. 2016. One loop to rule them all: the pingpong cycle and piRNA-guided silencing. Trends Biochem Sci 41: 324-337.

Czech B, Preall JB, McGinn J, Hannon GJ. 2013. A transcriptomewide RNAi screen in the Drosophila ovary reveals factors of the germline piRNA pathway. Mol Cell 50: 749-761.

Dequéant M-L, Fagegaltier D, Hu Y, Spirohn K, Simcox A, Hannon GJ, Perrimon N. 2015. Discovery of progenitor cell signatures by time-series synexpression analysis during Drosophila embryonic cell immortalization. Proc Natl Acad Sci 112: 12974-12979.

Dönertas D, Sienski G, Brennecke J. 2013. Drosophila Gtsf1 is an essential component of the Piwi-mediated transcriptional silencing complex. Genes Dev 27: 1693-1705.

Ghildiyal M, Zamore PD. 2009. Small silencing RNAs: an expanding universe. Nat Rev Genet 10: 94-108.

Gunawardane LS, Saito K, Nishida KM, Miyoshi K, Kawamura Y, Nagami T, Siomi H, Siomi MC. 2007. A slicer-mediated mechanism for repeat-associated siRNA $5^{\prime}$ end formation in Drosophila. Science 315: 1587-1590.

Haase AD, Fenoglio S, Muerdter F, Guzzardo PM, Czech B, Pappin DJ, Chen C, Gordon A, Hannon GJ. 2010. Probing the initiation and effector phases of the somatic piRNA pathway in Drosophila. Genes Dev 24: 2499-2504.

Han BW, Wang W, Li C, Weng Z, Zamore PD. 2015. Noncoding RNA. piRNA-guided transposon cleavage initiates Zucchinidependent, phased piRNA production. Science 348: 817-821.

Handler D, Meixner K, Pizka M, Lauss K, Schmied C, Gruber FS, Brennecke J. 2013. The genetic makeup of the Drosophila piRNA pathway. Mol Cell 50: 762-777.

Hashim A, Rizzo F, Marchese G, Ravo M, Tarallo R, Nassa G, Giurato G, Santamaria G, Cordella A, Cantarella C, et al. 2014. RNA sequencing identifies specific PIWI-interacting small non-coding RNA expression patterns in breast cancer. Oncotarget 5: 9901-9910.

Hogeveen KN, Sassone-Corsi P. 2006. Regulation of gene expression in post-meiotic male germ cells: CREM-signalling pathways and male fertility. Hum Fertil (Camb) 9: 73-79.

Homolka D, Pandey RR, Goriaux C, Brasset E, Vaury C, Sachidanandam R, Fauvarque M-O, Pillai RS. 2015. PIWI slicing and RNA elements in precursors instruct directional primary piRNA biogenesis. Cell Rep 12: 418-428.

Hudson AM, Mannix KM, Cooley L. 2015. Actin cytoskeletal organization in Drosophila germline ring canals depends on Kelch function in a Cullin-RING E3 ligase. Genetics 201: 1117-1131.

Janic A, Mendizabal L, Llamazares S, Rossell D, Gonzalez C. 2010. Ectopic expression of germline genes drives malignant brain tumor growth in Drosophila. Science 330: 1824-1827.

Kibanov MV, Egorova KS, Ryazansky SS, Sokolova OA, Kotov AA, Olenkina OM, Stolyarenko AD, Gvozdev VA, Olenina LV. 2011. A novel organelle, the piNG-body, in the nuage of Drosophila male germ cells is associated with piRNA-mediated gene silencing. Mol Biol Cell 22: 3410-3419.

Kim A, Terzian C, Santamaria P, Pélisson A, Purd'homme N, Bucheton A. 1994. Retroviruses in invertebrates: the gypsy retrotransposon is apparently an infectious retrovirus of Drosophila melanogaster. Proc Natl Acad Sci 91: 1285-1289.

Laborde E. 2010. Glutathione transferases as mediators of signaling pathways involved in cell proliferation and cell death. Cell Death Differ 17: 1373-1380.

Langmead B, Trapnell C, Pop M, Salzberg SL. 2009. Ultrafast and memory-efficient alignment of short DNA sequences to the human genome. Genome Biol 10: R25.
Lécher P, Bucheton A, Pélisson A. 1997. Expression of the Drosophila retrovirus gypsy as ultrastructurally detectable particles in the ovaries of flies carrying a permissive flamenco allele. $J$ Gen Virol 78: 2379-2388.

Liang L, Diehl-Jones W, Lasko P. 1994. Localization of vasa protein to the Drosophila pole plasm is independent of its RNA-binding and helicase activities. Development 120: 1201-1211.

Liu X, Gong H, Huang K. 2013. Oncogenic role of kinesin proteins and targeting kinesin therapy. Cancer Sci 104: 651-656.

Malone CD, Brennecke J, Dus M, Stark A, McCombie WR, Sachidanandam R, Hannon GJ. 2009. Specialized piRNA pathways act in germline and somatic tissues of the Drosophila ovary. Cell 137: 522-535.

Malone C, Brennecke J, Czech B, Aravin A, Hannon GJ. 2012. Preparation of small RNA libraries for high-throughput sequencing. Cold Spring Harb Protoc 2012: 1067-1077.

Meier K, Mathieu E-L, Finkernagel F, Reuter LM, Scharfe M, Doehlemann G, Jarek M, Brehm A. 2012. LINT, a novel dL (3)mbt-containing complex, represses malignant brain tumour signature genes. PLoS Genet 8: e1002676.

Mohn F, Handler D, Brennecke J. 2015. Noncoding RNA. piRNAguided slicing specifies transcripts for Zucchini-dependent, phased piRNA biogenesis. Science 348: 812-817.

Muerdter F, Guzzardo PM, Gillis J, Luo Y, Yu Y, Chen C, Fekete R, Hannon GJ. 2013. A genome-wide RNAi screen draws a genetic framework for transposon control and primary piRNA biogenesis in Drosophila. Mol Cell 50: 736-748.

Nagao A, Mituyama T, Huang H, Chen D, Siomi MC, Siomi H. 2010. Biogenesis pathways of piRNAs loaded onto AGO3 in the Drosophila testis. RNA 16: 2503-2515.

Ohtani H, Iwasaki YW, Shibuya A, Siomi H, Siomi MC, Saito K. 2013. DmGTSF1 is necessary for Piwi-piRISC-mediated transcriptional transposon silencing in the Drosophila ovary. Genes Dev 27: 1656-1661.

Olivieri D, Sykora MM, Sachidanandam R, Mechtler K, Brennecke J. 2010. An in vivo RNAi assay identifies major genetic and cellular requirements for primary piRNA biogenesis in Drosophila. EMBO I 29: 3301-3317.

Parisi MJ, Gupta V, Sturgill D, Warren JT, Jallon J-M, Malone JH, Zhang Y, Gilbert LI, Oliver B. 2010. Germline-dependent gene expression in distant non-gonadal somatic tissues of Drosophila. BMC Genomics 11: 346.

Perezgasga L, Jiang J, Bolival B, Hiller M, Benson E, Fuller MT, White-Cooper H. 2004. Regulation of transcription of meiotic cell cycle and terminal differentiation genes by the testis-specific Zn-finger protein matotopetli. Development 131: 1691-1702.

Polesello C, Tapon N. 2007. Salvador-warts-hippo signaling promotes Drosophila posterior follicle cell maturation downstream of notch. Curr Biol 17: 1864-1870.

Quinlan AR, Hall IM. 2010. BEDTools: a flexible suite of utilities for comparing genomic features. Bioinformatics 26: 841-842.

Richter C, Oktaba K, Steinmann J, Müller J, Knoblich JA. 2011. The tumour suppressor L(3) mbt inhibits neuroepithelial proliferation and acts on insulator elements. Nat Cell Biol 13: 1029-1039.

Robine N, Lau NC, Balla S, Jin Z, Okamura K, Kuramochi-Miyagawa S, Blower MD, Lai EC. 2009. A broadly conserved pathway generates $3^{\prime}$ UTR-directed primary piRNAs. Curr Biol 19: 2066-2076.

Robinett CC, Vaughan AG, Knapp J-M, Baker BS. 2010. Sex and the single cell. II. There is a time and place for sex. PLOS Biol 8: e1000365. 
Ross RJ, Weiner MM, Lin H. 2014. PIWI proteins and PIWI-interacting RNAs in the soma. Nature 505: 353-359.

Rozhkov NV, Hammell M, Hannon GJ. 2013. Multiple roles for Piwi in silencing Drosophila transposons. Genes Dev 27: 400-412.

Saito K, Inagaki S, Mituyama T, Kawamura Y, Ono Y, Sakota E, Kotani H, Asai K, Siomi H, Siomi MC. 2009. A regulatory circuit for piwi by the large Maf gene traffic jam in Drosophila. Nature 461: 1296-1299.

Saito K, Ishizu H, Komai M, Kotani H, Kawamura Y, Nishida KM, Siomi H, Siomi MC. 2010. Roles for the Yb body components Armitage and $\mathrm{Yb}$ in primary piRNA biogenesis in Drosophila. Genes Dev 24: 2493-2498.

Senti K-A, Jurczak D, Sachidanandam R, Brennecke J. 2015. piRNA-guided slicing of transposon transcripts enforces their transcriptional silencing via specifying the nuclear piRNA repertoire. Genes Dev 29: 1747-1762.

Sienski G, Dönertas D, Brennecke J. 2012. Transcriptional silencing of transposons by Piwi and maelstrom and its impact on chromatin state and gene expression. Cell 151: 964-980.

Sienski G, Batki J, Senti K-A, Dönertas D, Tirian L, Meixner K, Brennecke J. 2015. Silencio/CG9754 connects the Piwi-piRNA complex to the cellular heterochromatin machinery. Genes Dev 29: 2258-2271.

Simcox A, Mitra S, Truesdell S, Paul L, Chen T, Butchar JP, Justiniano S. 2008. Efficient genetic method for establishing Drosophila cell lines unlocks the potential to create lines of specific genotypes. PLoS Genet 4: e1000142.
Simpson AJG, Caballero OL, Jungbluth A, Chen Y-T, Old LJ. 2005. Cancer/testis antigens, gametogenesis and cancer. Nat Rev Cancer 5: 615-625.

Siomi MC, Sato K, Pezic D, Aravin AA. 2011. PIWI-interacting small RNAs: the vanguard of genome defence. Nat Rev Mol Cell Biol 12: 246-258.

Song SU, Kurkulos M, Boeke JD, Corces VG. 1997. Infection of the germ line by retroviral particles produced in the follicle cells: a possible mechanism for the mobilization of the gypsy retroelement of Drosophila. Development 124: 27892798.

Wang S, Gao Y, Song X, Ma X, Zhu X, Mao Y, Yang Z, Ni J, Li H, Malanowski KE, et al. 2015a. Wnt signaling-mediated redox regulation maintains the germ line stem cell differentiation niche. Elife 4: e08174.

Wang W, Han BW, Tipping C, Ge DT, Zhang Z, Weng Z, Zamore PD. 2015b. Slicing and binding by Ago3 or Aub trigger Piwibound piRNA production by distinct mechanisms. Mol Cell 59: 819-830.

Yu Y, Gu J, Jin Y, Luo Y, Preall JB, Ma J, Czech B, Hannon GJ. 2015. Panoramix enforces piRNA-dependent cotranscriptional silencing. Science 350: 339-342.

Zhang C, Robinson BS, Xu W, Yang L, Yao B, Zhao H, Byun PK, Jin P, Veraksa A, Moberg KH. 2015. The ecdysone receptor coactivator Taiman links Yorkie to transcriptional control of germline stem cell factors in somatic tissue. Dev Cell 34: 168-180. 


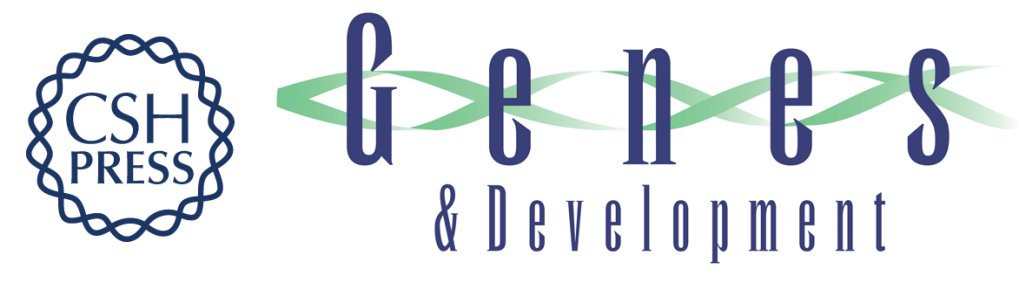

\section{Oncogenic transformation of Drosophila somatic cells induces a functional piRNA pathway}

Delphine Fagegaltier, Ilaria Falciatori, Benjamin Czech, et al.

Genes Dev. 2016, 30:

Access the most recent version at doi:10.1101/gad.284927.116

Supplemental http://genesdev.cshlp.org/content/suppl/2016/07/29/30.14.1623.DC1
Material

References This article cites 60 articles, 25 of which can be accessed free at: http://genesdev.cshlp.org/content/30/14/1623.full.html\#ref-list-1

Creative This article is distributed exclusively by Cold Spring Harbor Laboratory Press for the first Commons six months after the full-issue publication date (see

License http://genesdev.cshlp.org/site/misc/terms.xhtml). After six months, it is available under a Creative Commons License (Attribution-NonCommercial 4.0 International), as described at http://creativecommons.org/licenses/by-nc/4.0/.

Email Alerting Receive free email alerts when new articles cite this article - sign up in the box at the top Service right corner of the article or click here.

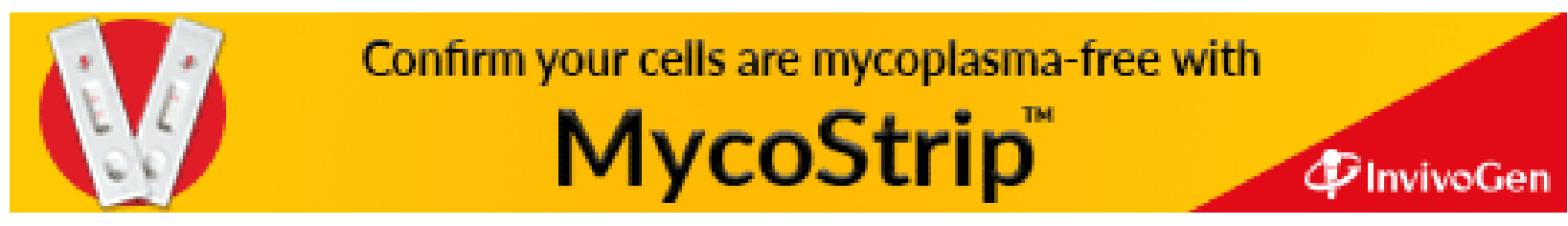

